Working Paper No. 552, 2001

Developing and Distributing Essential Medicines to Poor Countries: The DEFEND Proposal

by Mattias Ganslandt, Keith E. Maskus and Eina V. Wong

IUI, The Research Institute of Industrial Economics

P.O. Box 5501

SE-114 85 Stockholm

Sweden 


\title{
DEVELOPING AND DISTRIBUTING ESSENTIAL MEDICINES TO POOR COUNTRIES: THE DEFEND PROPOSAL
}

\author{
Mattias Ganslandt \\ Keith E. Maskus \\ Eina V. Wong
}

\begin{abstract}
:
The poorest nations of the world suffer from extreme disease burdens, which go largely untreated because weak incomes and the prevailing system of intellectual property rights fail to provide sufficient incentives to develop new treatments and distribute them at low cost. Recent price reductions for HIV/AIDS drugs are encouraging but offer only a limited solution. We discuss the economic tradeoffs involved in supporting drug and vaccine research through exclusive rights and distributing the fruits of that research to poor countries. We offer a proposal to overcome these incentive problems. Our DEFEND ("Developing Economies' Fund for Essential New Drugs") proposal would work within the existing international legal structure but significantly would raise the returns to $R \& D$ in critical medicines and expand distribution programs. A public international organization would purchase the license rights for designated areas and distribute the drugs at low cost with a required co-payment from local governments. Furthermore, governments would restrict parallel trade to support desirable price discrimination. Costs would be funded largely by increased foreign assistance from the developed nations, but these costs would be low in relation to current aid budgets. We believe a strong program could be mounted for $\$ 8$ billion to $\$ 12$ billion per year and would be an extremely effective use of foreign aid.
\end{abstract}

Keywords: drug pricing, essential medicines, parallel imports, developing countries, patents

JEL codes: F13, I12, I18, H51, H73,

Ganslandt: IUI (The Research Institute of Industrial Economics), P.O. Box 5501, SE11485 Stockholm, SWEDEN; email mattias.ganslandt@iui.se. Maskus and Wong: Department of Economics, UCB 256, University of Colorado, Boulder, CO 80309-0256, USA; email maskus@spot.colorado.edu 


\section{Introduction}

Perhaps the most critical task currently facing the global economy is to devise mechanisms that both encourage research aimed at finding treatments for diseases that are common in impoverished nations and that achieve widespread international distribution of these treatments at sufficiently low costs to be effective and affordable. This issue has achieved prominence by virtue of the severe epidemic of the HIV virus, which inevitably leads to the onset of AIDS, in Sub-Saharan Africa and, increasingly, in South Asia and Southeast Asia.

HIV/AIDS is not the only disease that plagues poor nations, where malaria, tuberculosis, and other maladies are equally lethal and debilitating. Indeed, HIV/AIDS is unusual in that strong incentives for pharmaceutical companies to develop treatments for sufferers in high-income economies have resulted in medicines that effectively permit patients to function well for many years before onset of the disease. In that regard, the current debate is about how best to transfer these medicines to poor countries. In contrast, there is virtually no $R \& D$ aimed at producing new treatments for malaria or tuberculosis. This situation arises largely because those who suffer are overwhelmingly poor and could not afford medicines in sufficient quantities to cover R\&D costs. The problem is accentuated by weak patent protection in potential markets, further reducing the willingness of pharmaceutical enterprises to develop new drugs and vaccines.

To put it in economic terms, under the current system the incentives to achieve efficient dynamic and static provision of medicines are grossly inadequate in the face of massive poverty. To deal with this problem essentially two programs have been advanced in recent years, which are considerably at odds with each other. On the one 
hand, the Agreement on Trade-Related Aspects of Intellectual Property Rights (TRIPS) within the World Trade Organization requires member countries to grant and enforce patents for new pharmaceutical products (Maskus, 2000a; Gorlin, 1999). More precisely, developers of new drugs have enjoyed exclusive marketing rights (EMRs) in all WTO members since January 1, 1995. While product patents are not required until the year 2005 in the least-developed countries, EMRs provide similar protection. Various economic studies suggest that this new regime could raise prices of new drugs markedly in developing countries (Watal, 1999; Fink, 2000; Lanjouw, 1998; Subramanian 1995), though substantial uncertainty remains on this point. ${ }^{1}$ Thus, some possibility exists that patents will raise incentives for $R \& D$ in these neglected diseases (Lanjouw, 1998). However, this policy shift does nothing directly to increase incomes of sufferers, who would, if anything, become less able to afford new medicines. ${ }^{2}$

Thus, on the other hand, considerable pressure has mounted on pharmaceutical companies to provide their drugs at marginal production cost (or less) to poor countries. Several firms have responded, such as Merck \& Co., Bristol-Myers Squibb Co., GlaxoSmithKline PLC, and Abbott Laboratories. For example, Merck \& Co. recently announced it would reduce the prices of two AIDS-controlling drugs in Africa by $40 \%$ to $55 \%$, adding to sharp price cuts announced in $2000 .^{3}$ Abbott announced that it would sell its two AIDS drugs, Norvir and Kaletra, at a price that would earn the company no profit. ${ }^{4}$ In some degree these actions are a competitive response to offers by two Indian

\footnotetext{
${ }^{1}$ See Rozek and Berkowitz (1998) for a dissenting view.

${ }^{2}$ See Abbott (2000) for a legal analysis of the pharmaceutical aspects of TRIPS, claiming that the agreement raises difficult contradictions between the trading system and needs for protecting public health.

${ }^{3}$ Wall Street Journal, "Price War Breaks Out Over AIDS Drugs in Africa as Generics Present Challenge," 7 March 2001.

${ }^{4}$ Wall Street Journal, "Abbott to Cut Prices on AIDS Drugs Distributed in Sub-Saharan Africa," 27 March 2001.
} 
producers of generic AIDS drugs, Cipla Ltd. and Hetero Drugs Ltd., to provide medicines at even lower prices. As we note in the next section, however, even at these prices the drugs may be beyond the reach of most patients.

The research-intensive pharmaceutical firms that invented these drugs have three concerns about low-cost distribution programs. First, provision at marginal cost or lower adds nothing to their ability to cover the fixed costs of R\&D. Second, while they may be willing to circulate their medicines cheaply, the firms are anxious to retain the exclusive distribution rights inherent in patents and EMRs. Indeed, this preference to forestall generic competition is the root of the ongoing lawsuit raised by 39 drug makers in South Africa aimed at striking down that country's 1997 Medicines and Related Substances Control Act. ${ }^{5}$

Third, and perhaps most significantly, original drug developers worry that the availability of far-cheaper treatments in poor countries could erode their price-setting power in rich countries. This erosion could happen directly through unauthorized parallel trade in drugs or indirectly through political pressure mounted by patients and insurance companies on health authorities to require significant price reductions. Because the vast bulk of returns to R\&D are realized in the United States, the European Union, and other industrialized nations, pharmaceutical companies argue that such price spillovers would significantly hamper their incentives to develop new treatments. ${ }^{6}$

Control over patent rights in AIDS treatments is now before the WTO in a dispute raised by the United States against Brazil in February 2001. Under Article 71 of Brazil's 1997 Patent Act, foreign firms must manufacture patented drugs within Brazil before

\footnotetext{
${ }^{5}$ Wall Street Journal, "Big Drug Firms Defend Right to Patents on AIDS Drugs in South African Court," 6 March 2001.
} 
three years have elapsed from patent grant. Failure to meet these "working requirements" could result in an order by the Brazilian Health Ministry to local firms to manufacture generic substitutes, a threat that currently faces makers of the AIDS drugs Efavirenz (Merck \& Co.) and Nelfinavir (Roche). ${ }^{7}$ The TRIPS Agreement would seem to restrict considerably Brazil's ability to enforce working requirements. Thus, this case could set an important precedent concerning the ability of countries to limit private rights to exploit patents.

Putting these elements together, drug development and distribution involve tradeoffs that implicate important principles underlying protection of intellectual property rights (IPRs). To begin, there is a strong global public interest in providing sufficient incentives for the continual development of new medical treatments for diseases afflicting the poor. Within the intellectual property system these incentives stem largely from exclusive production and distribution rights provided by EMRs and patents.

However, such rights may be inadequate for meeting the needs of extremely poor patients that do not have enough income to purchase them even at low prices.

Further, such rights are national or territorial in scope, meaning that governments may choose their own regimes concerning whether rights holders can prevent parallel trade. $^{8}$ Indeed, the TRIPS Agreement affirms that countries have the authority to decide whether exclusive rights are exhausted at national borders. The threat that products may be shipped from lower-priced countries to higher-priced countries reduces the enthusiasm of rights holders to supply them at low cost.

\footnotetext{
${ }^{6}$ New York Times, "Group Says Discount AIDS Drugs Endanger Research," 13 February 2001.

${ }^{7}$ New York Times, "Brazil May Defy U.S. and Make More AIDS Drugs," 14 February 2001.

${ }^{8}$ Maskus (2000b) provides an overview of the economics of parallel trade.
} 
The current system generates numerous undesirable outcomes. First, there are not enough incentives to develop new treatments for endemic diseases in impoverished markets. The resulting high rates of infection and contagion impose external costs on others both within and across borders, in part because of lower productivity. Surely the industrialized economies suffer some costs from slower growth in the afflicted countries. In this sense, development and provision of effective drugs is a global public good.

Second, demands that drugs be provided at marginal cost in some countries force patients in higher-price countries to accept a disproportionate share of the burden of financing $R \& D$ cost recovery. Put another way, patients in lower-cost nations effectively free ride on the pricing systems of the United States and other industrialized nations. In fact, the free riding has at least two dimensions. In addition to the low prices in poor countries, price controls in Canada, Europe, and elsewhere mean that patients in those nations provide limited contributions to recovering fixed R\&D costs. ${ }^{9}$ In that context, American patients and insurance companies bear the brunt of paying for R\&D and any losses associated with distribution programs abroad. Thus, neither pharmaceutical companies nor their patients may be expected to embrace the costs of distribution and development.

Third, pharmaceutical firms chronically under-supply the medicinal needs of poor countries, partly because of limited exclusivity in rights, including the need to restrain parallel trade.

These problems point squarely at the need for further public involvement in encouraging new drugs and in procuring and distributing medicines. In this paper we set 
out a proposal for addressing the fundamental problems in a manner that is least disruptive to the international system of IPRs. It involves, first, increases in public assistance or public health budgets in the rich countries in order to fund purchases by a body such as the World Health Organization (WHO) of exclusive licenses to distribute selected medicines in poor countries. The license fees should be sufficient to cover all or a substantial portion of fixed $R \& D$ costs, thereby establishing a strong incentive for pharmaceutical and vaccine firms to produce new treatments. In terms of distributing these products in poor markets, the WHO would be free to do so at a per-unit price below its marginal private costs in recognition of the external benefits from improved health status. Finally, each country or region that avails itself of this program would be required to assert strong controls on parallel exports in order to safeguard prices in markets in high-income economies.

The procurement portion of our proposal is similar to the idea for a vaccinepurchase fund put forward by Sachs, et al (1999). However, their proposal involves a guaranteed price per dosage without contemplating difficulties in effecting distribution or in segmenting markets. It also bears similarity to current proposals for ensuring "tiered pricing" of existing HIV/AIDS drugs (Barton, 2001; Subramanian, 2001) but these programs make no provisions for managing dynamic R\&D incentives. Thus, we offer our proposal as complementary to both of these ideas.

In the next section we provide basic evidence on the extent of the $R \& D$, distribution, and pricing problems in the current system. In Section Three we discuss the economics of optimal provision in recognition of the significant externalities involved.

\footnotetext{
${ }^{9}$ The general nature of this problem is reflected in recent legislative proposals in the United States partially to deregulate restrictions on parallel imports of prescription pharmaceuticals in order to permit U.S.
} 
In Section Four we set out the proposal explicitly and discuss ideas for its implementation. We conclude in Section Five.

\section{Scope of the Problem}

The incidence and costs of endemic diseases in poor countries are staggering. These maladies not only afflict high rates of mortality but also significantly reduce the health status and productivity of the affected population. Table 1 provides estimates by the World Health Organization of deaths and productive time lost (measured in disabilityadjusted life years, or DALYs) to three major diseases in 1999 for Africa, the Americas, and Southeast Asia. HIV/AIDS is thought to have killed 2.7 million people globally in 1999, with 2.2 million of these in Africa. It claimed 81,000 victims in the Americas and 360,000 victims in Southeast Asia, where the problem is rising rapidly. The disease was also responsible for 89.8 million adjusted life-years lost to morbidity and mortality. Again, this loss was concentrated in Africa, where 74.4 million life-years were foregone.

The victims of tuberculosis (TB) are spread more evenly through the developing world. It killed 1.7 million people in 1999, with 357,000 in Africa, 59,000 in the Americas, and 723,000 in Southeast Asia. Importantly, TB is frequently contracted by HIV/AIDS sufferers and surveys suggest that up to 70 percent of tuberculosis patients are infected with HIV. ${ }^{10}$ Such joint cases are concentrated in Sub-Saharan Africa. Malaria is also concentrated in Africa, killing perhaps 953,000 people in 1999 and sacrificing 36.8 million life-years. According to the WHO, the direct and indirect costs of malaria in

\footnotetext{
patients to gain access to cheaper foreign sources of supply.

${ }^{10}$ UNAIDS Press Release: "World TB Day 2001: Access to TB Cure a Human Rights Imperative," at www.unaids.org/whatsnew/press/eng/pressarc01/TB_220301.html.
} 
Sub-Saharan Africa exceed $\$ 2$ billion per year. ${ }^{11}$ Malaria is not at this time a large problem in the Americas.

Additional figures illustrate the scope of HIV/AIDS in Africa. There are now 25.3 million Africans living with HIV or AIDS. ${ }^{12}$ In eight countries at least 15 percent of adults are infected. Infection rates in African women in their early 20s are three times higher than in men of the same age group. In Botswana, 36 percent of adults are now infected with HIV, while in South African the figure is 20 percent. South Africa has 4.2 million infected people, the largest number in the world. These figures are rising at alarming rates. ${ }^{13}$ Among the 1.4 million children under the age of 15 living with HIV/AIDS at the end of 2000, 1.1 million reside in Sub-Saharan Africa. Perhaps 12.1 million children have been orphaned by the disease in that region.

Economic studies suggest that South African GDP will be perhaps 17 percent lower in 2010 than it would be without AIDS, removing \$22 billion in output from the economy. In Botswana, there could be a 13-15 percent reduction in the income of the poorest households. The fiscal cost of the disease is also debilitating. It has been estimated that in seven of 16 African countries surveyed, public health spending for AIDS alone exceeded two percent of GDP in 1997, against total spending for health care of three to five percent of GDP.

These three diseases display different characteristics in terms of treatment costs and R\&D incentives. Tuberculosis is curable with a single drug treatment that costs as

\footnotetext{
${ }^{11}$ WHO, "Fact Sheet: Malaria," at www.who.int/inf-fs/en/fact094.html.

12 These figures are from "Fact Sheet: HIV/AIDS in Africa," at www.unaids.org/fact_sheet/files/FS_Africa.htm. There are also 5.8 million living with HIV/AIDS in South Asia and Southeast Asia, see "Regional HIV/AIDS Statistics and Features, End of 2000," www.unaids.org/wac/2000/wad00/files/WAD_epidemic_report/css/WAD_epidemic_report_5.htm. ${ }^{13}$ At the same time, successful prevention programs in a few African countries, such as Uganda, have reduced national infection rates.
} 
little as \$10-15 per patient. ${ }^{14}$ Unfortunately, TB is an airborne virus and in crowded environments with large numbers of sufferers, it is difficult and expensive to achieve eradication. The effective approach to TB is procurement programs to purchase and distribute these treatments widely in order to eradicate its presence, a task that lies beyond the economic reach of many health ministries in poor countries. Note also that there is little research into new treatments for TB. The World Health Organization (1996) estimated that of the $\$ 56$ billion spent globally on medical R\&D in 1994, less than 0.2 percent was spent on TB, diarrheal maladies, and pneumonia. Virtually all of the latter research was performed by public agencies and military authorities.

Malaria can be partially prevented through sanitation programs and prophylaxis, while it can be treated with available drugs. Again, these drugs may be out of the reach of poor patients. Moreover, because the disease tends to build resistance to drugs over time there is a continuous need for research into new medicines. The most effective long-term solution, in addition to vector control strategies, is the development of malaria vaccines, which could be administered to children. ${ }^{15}$ However, there is insufficient R\&D in anti-malarial vaccines or drugs. Sachs, et al (1999) cite a Wellcome Trust study that found that public and non-profit malaria research amounted to $\$ 84$ million in 1993, with vaccine research amounting to a small portion of that spending. Private sector spending was lower still. We should note that more research into vaccines and anti-malarial drugs is underway under the auspices of the Multilateral Initiative on Malaria, involving the UNDP, the World Bank, and the WHO, and the Medicines for Malaria Venture, a publicprivate sector cooperative initiative. However, funding for the former comes to perhaps

\footnotetext{
${ }^{14}$ See UNAIDS, note 9 supra.

${ }^{15}$ Sachs, et al (1999).
} 
$\$ 3$ million per year and the latter group is soliciting support from foundations in the hopes of achieving $\$ 30$ million per year. These amounts seem inadequate for the job, given the underlying costs of developing and testing new drugs, and also fail to exploit private incentives within the intellectual property system.

As a final observation on the current problem, note that even though many pharmaceutical firms have slashed their prices for HIV/AIDS treatments in poor African countries, the prices on offer still do not reduce per-patient cost burdens relative to those in rich nations. In Panel A of Table 2 we show the current average prices in U.S. dollars for six AIDS drugs of an annual treatment for a single patient in the United States, Sweden, and South Africa. For South Africa we show both the prices offered by pharmaceutical companies that own patents on these drugs in the United States and prices offered by Indian generic producers. For example, the drug Viramune costs $\$ 3,508$ in the United States, $\$ 2,565$ in Sweden, and is now offered at $\$ 483$ (original version) and $\$ 340$ (generic version) in South Africa. In that context the prices are far lower in South Africa than in the United States. ${ }^{16}$

However, as shown in Panel B, when these prices are divided by the U.S.-dollar value of per-capita GDP in 1998, the burden of these drugs in income units is essentially the same in all three markets. Indeed, the price as a proportion of per-capita GDP is lower in South Africa than in the United States only in two drugs and is higher in three. ${ }^{17}$

\footnotetext{
${ }^{16}$ Note that Bristol-Myers Squibb Co. quite recently offered Zerit to South Africa for $\$ 54$ per patient per year, making that price much less than indicated. See Wall Street Journal, "Bristol-Myers Squibb Offers to Sell AIDS Drugs in Africa at Below Cost," 15 March 2001.

${ }^{17}$ We use 1998 GDP per capita for this purpose because it is the latest year available. Note that the South African Rand depreciated by 29 percent (and the Swedish Krona by 18 percent) relative to the dollar from 1998 to 2001, making the Rand-denominated burdens yet higher to the extent that nominal depreciation reflects GDP changes.
} 
The range of prices of available generic substitutes generally lies below the original manufacturer's price in South Africa, but not in all cases.

\section{The Economics of Developing and Distributing Drugs}

A key health-policy objective of most countries is to give patients access to existing pharmaceutical drugs at a reasonable cost. From a welfare point of view, effective medicines have a value both to the individual and to society as a whole. First and foremost, pharmaceutical drugs have value to the individual, in some cases as a treatment of symptoms, in other cases as a cure. But they also have additional value to society as a method to limit the risk for healthy individuals to be harmed by infectious diseases. Total welfare is maximized in the short-run if existing drugs are provided at a price equal to, or in some cases below, the marginal cost of production.

The problem, however, is that developing new drugs typically involves substantial investments in research and development. The average cost to develop a new pharmaceutical drug is approximately $\$ 300$ million and in some cases substantially higher. ${ }^{18}$ These costs are mainly fixed and sunk once the drug is developed.

If prices were set equal to, or even below, marginal cost of production the pharmaceutical companies would not be able to recoup their investments and the economic incentives for research and development would disappear. The result of marginal-cost-pricing is, therefore, that too little investment in research and development takes place and too few drugs are developed in the long run. To correct for this market

\footnotetext{
${ }^{18}$ Sachs, et al (1999) estimate the average cost for a new drug to be $\$ 300$ million and predict that developing vaccines for HIV, turberculosis and malaria would "potentially cost several times as much given the scientific challenges involved.", p. 8.
} 
imperfection, patents exist to reduce competition and allow pharmaceutical companies to exercise some market power in order to recover their investments in R\&D.

The welfare optimization problem in a closed economy, thus, involves a trade-off between giving patients access to existing drugs at reasonable costs versus profits for pharmaceutical companies, which are incentives for researching and developing new drugs in the future. Unfortunately, monopoly pricing of existing drugs causes static problems of insufficient market access for patients. Such problems can be solved, at least in theory, if the short-run and long-run objectives are separated. The first-best solution from a welfare perspective is to reward new innovations with a fixed lump-sum transfer to the innovating firm and to distribute existing drugs at competitive, or even below competitive prices.

While a policy to separate fixed and variable costs of pharmaceutical drug production might be unpractical or even impossible to implement in most cases, it can be useful in particular situations. More precisely, cost-based pricing and lump-sum payments for innovations could be the only way to achieve both the current and future health objectives in the poorest countries of the world.

So far we have discussed the problem of static distortions and dynamic efficiency in general terms. It is, however, important to recognize the international dimension of this issue. First of all, the trade-off between different objectives is not identical in all countries and, consequently, the optimal policy differs across nations. Moreover, in a global economy with trade in pharmaceutical products, health-care policy in one country has important implications for policy in other countries. 
Starting with the issue of different objectives in industrialized and developing countries, it is crucial to note that the weights put on short-run and long-run objectives depend on several factors and the optimum is likely to vary across countries with different levels of income. Countries with high average income are likely to put more weight on new and improved drugs relative to countries with medium or low average income. As long as future drugs are normal goods, rich countries can be expected to have a higher willingness to pay for research and development. Lower rates of time preference in developed countries could also affect the trade-off in the same direction. Governments in industrialized countries are therefore more willing to accept high profits in the pharmaceutical industry to promote future innovations and improved drugs, while governments in developing countries to a larger degree prefer to give patients access to existing drugs at low costs.

Restricting our attention to the pricing problem of pharmaceutical companies, the optimal prices in local markets typically depend on the price elasticity of demand as well as the potential for arbitrage between markets. If the average income differs across two segmented markets, optimal prices for a monopolist are likely to be different in the two locations. Giving rebates to consumers with low income is often profitable for the monopolist as long as the rebated price is above the marginal cost of production and the scope for re-sale to high-income consumers is limited. When discounts for a homogenous good are the same for all consumers within a specific market but vary across different markets the pricing strategy corresponds to third-degree price discrimination. Arbitrage between markets - often referred to as parallel imports - limits the scope for third-degree price discrimination. If both markets are served by the monopolist the 
price in the low-income country is likely to rise as a result of parallel trade, while the price in the high-income country is likely to fall. The pharmaceutical company receives less revenue from both the low-income as well as the high-income market when parallel imports result in equalized prices. With large differences in average income across markets, as is the case with developing and industrialized countries, it is quite possible that parallel trade makes it unprofitable to serve low-income markets. Under such circumstances, it is beneficial for all parties - more precisely a Pareto improvement - to restrict parallel imports and increase the degree of price discrimination. ${ }^{19}$

The trade regime affects not only the scope for monopoly price discrimination but also, and more generally, the range of differences in health policies in different countries. More precisely, parallel trade undermines the independence of health authorities in both industrialized and developing countries. In practice, most industrialized countries maintain a policy that allows the pharmaceutical companies to recover their investment in research and development through monopoly mark-ups on existing drugs primarily in the U.S., Japanese and European markets. In this context, it is clear that marginal-cost-based pricing in developing countries could have serious effects on the incentives to introduce drugs in the poorest countries unless the price spillover to industrialized countries is limited.

A necessary, but not sufficient, condition for an effective solution to the accessdevelopment problem for pharmaceutical products in developing countries is, therefore, to limit parallel exports from the developing countries as well as parallel imports into the industrialized countries.

\footnotetext{
${ }^{19}$ As noted in Varian (1988), this result is quite robust. If price discrimination results in a new market being opened up, then it is typically a Pareto-improving welfare enhancement. Hausman and MacKie-Mason
} 


\section{A Proposal for a Developing Economies' Fund for Essential New Drugs}

In this section we set out a new proposal that would help resolve the incentive problems plaguing development and dissemination of drugs under the current system. We term our initiative the DEFEND Proposal, for "Developing Economies' Fund for Essential New Drugs".

\subsection{Criteria}

The magnitude of the problem with HIV/AIDS, TB and malaria in the least developed countries, particularly in Sub-Saharan Africa, suggests that any proposal to solve the problem must meet several criteria.

First and foremost, giving the poorest countries access to existing therapies and drugs would require prices equal to, or in most cases below, marginal cost. The magnitude of the epidemic and the low level of income in the poorest countries make low prices a necessity. This point can easily be illustrated with a hypothetical experiment. Assuming that all HIV-positive individuals in sub-Saharan Africa were treated with a typical AIDS cocktail therapy (Crixivan, AZT and 3TC) bought at US prices, the total expenditure for these drugs would be more than total GDP in the Sub-Saharan countries put together. ${ }^{20}$

Moreover, for countries with very low median income it can be expected that even a small or moderate monopoly mark-up would generate a substantial allocative

(1988) study this problem in the context of new patents.

${ }^{20}$ The total GDP in sub-Saharan Africa is approximately $\$ 285$ billion according to the most recent figures from the World Bank (World Economic Indicators 2000). A therapy with Crixivan, AZT and 3TC is 
inefficiency and dead-weight loss. This is a fundamental reason to separate the incentives for development of new drugs from the distribution of existing drugs. The distribution of existing drugs in the poorest countries should, therefore, be founded on cost-based pricing while the incentives for development of new drugs has to be effected by other means. We will turn to this latter problem next.

The second criterion for good policy is that it has to include incentives to encourage innovation and development of new therapies and drugs. The problem is not that it is too profitable to innovate for poor countries, but rather that it is too unprofitable. For the world's three most deadly infectious diseases - AIDS, tuberculosis and malaria effective vaccines still have to be invented. Moreover, most of the existing treatments for HIV/AIDS have serious and sometimes lethal side effects. In other words, more research on new drugs as well as improvements of existing drugs for the poorest countries is needed in the future.

The typical incentive for research and development of new pharmaceutical products is the prospect of future profits. But we have previously argued that it would be inexpedient and unrealistic to generate sufficient incentives for $\mathrm{R} \& \mathrm{D}$ through monopoly mark-ups in the world's poorest countries. There are three reasons why reliance on future monopoly profits is not a desirable incentive scheme: the monopoly mark-up is distortionary, the potential rents are too small and the political risks involved are too large for the pharmaceutical companies (e.g. the risk of compulsory licencing or generic substitution). The solution to these problems is to design a scheme with fixed lump-sum payments for new innovations, partly subsidized by the industrialized countries with a 
long-term guarantee to the pharmaceutical companies that they will receive some reasonable return on their investment in new and effective drugs.

The third criterion any realistic proposal must meet is that it has to be developed within the limits of international law and treaties and must be supported by established international organizations. The most important examples are the rules of the WTO and the offices of the WHO. In particular, the TRIPS agreement requires all parties to give patent protection to new innovations, including pharmaceutical products. But it also leaves the question of the legality of parallel imports to national governments.

As we have previously stressed, the problem of access to existing and new drugs in the least developed countries is not only a question of trade, patents and pricing but also requires financial aid from industrialized countries. This latter task is best carried out as a coordinated program by the World Health Organization. The main functions of the WHO are to give worldwide health guidance, set global health standards, cooperate with governments to strengthen national health programs and, finally, to develop and transfer appropriate health technology, information and standards.

The fourth and final criterion is to limit coverage of inexpensive distribution to well-defined and restricted geographical areas. The health policies of most developed countries have to be taken as given and must be isolated from the strategy for access to pharmaceutical drugs in the least-developed countries. In order to avoid spillovers to the high-income, high-price OECD markets the policy should include official restrictions on parallel imports of the program drugs into the industrialized nations. Moreover, the leastdeveloped countries need to impose restrictions on parallel exports from their own markets in order to deter slippage into countries that are not designated as recipients. Put 
briefly, we envision a regime of regional exhaustion within the WHO-designated program areas but tight controls to prevent the low-cost drugs from escaping those areas.

\subsection{Outline of the Proposal}

In the previous section we stressed that a successful strategy to give people in developing countries access to effective medicines has to involve four components. First, the cost of giving patients access to existing drugs has to be separated from the incentives for pharmaceutical companies to improve and develop new drugs. Second, the financial incentives to invent new drugs for the world's least developed countries must be subsidized by the industrialized countries. Third, a coordinated strategy should be jointly financed by the developed countries and implemented by an established international organization within the limits of international treaties. Fourth, the strategy should be focused on the least-developed countries and price spillovers should be limited by restrictions on parallel exports. A fund for essential new drugs could potentially help to solve this problem.

The principal structure of the strategy would be an international fund managed by UNAIDS or WHO. With contribution from the developed - and possibly some middleincome developing countries - the fund would buy licenses to produce and sell patented essential drugs in those least-developed nations that choose to be part of the program. Contributions to the fund should be in the form of cash to finance current expenditure. Equally important would be binding commitments to pay for future drugs, in particular vaccines for HIV, TB and malaria. 
The program should be open to the least developed countries and all countries in Sub-Saharan Africa. ${ }^{21}$ Any government, international organization or non-governmental organization should be allowed to use the license in the participating countries under three conditions: the original patent is respected in non-participating markets, the distribution is restricted to patients in the participating countries and parallel trade to other markets is prohibited. ${ }^{22}$ The portfolio of licenses managed by the international fund should be limited to the most essential drugs. A board representing donors would regularly review the portfolio of current and future licenses.

Payments to patent holders should be in the form of a fixed, yearly, lump-sum transfer that would feature three characteristics. First, it should guarantee successful drug and vaccine developers a net present value over the life of the program that should equal expected R\&D costs. Second, it should be positively related to the social value (associated with reduced mortality, morbidity, and spillovers) of the drug in the licensed areas in order to tie R\&D incentives to underlying needs. Third, given that there may be broader markets for the new drugs and vaccines, it should be positively related to the global share of patients in the licensed areas.

In addition to paying patent holders for licenses, the Fund could provide subsidies to purchase and distribute essential drugs in countries where a large fraction of the population is infected or production cost of the drug is too high in relation to the average income. For available life-extending treatments - such as the existing AIDS therapies - a

\footnotetext{
${ }^{21}$ The World Bank defines low-income economies as countries with a 1999 GNP per capita of $\$ 755$ or less. In the most recent classification there were 64 countries in this category.

${ }^{22}$ Production and distribution under these licenses should not be allowed for companies that produce generic substitutes competing with the patented product in non-participating markets. The main reason for this restraint is to avoid strategic spillovers due to cost efficiencies in the production of the licensed product. If, for example, a firm in country A were certified to produce a drug under a publicly procured
} 
possible policy would be to subsidize purchases so that a specific treatment does not cost more than a pre-defined share (e.g. forty percent) of the average GNP per capita in a particular country (the remainder would have to be financed by the local government, NGOs, donors or the patients as a form of co-payment). For vaccines these purchases could be subsidized to a larger degree (up to 100 percent) as widespread access to vaccines has positive externalities both in the local and global community.

\subsection{Implementation of the Proposal}

The implementation of the proposal could be gradual. Starting with HIV/AIDS treatment, the Fund could buy a portfolio of five or six licenses for the most important AIDS/HIV drugs. ${ }^{23}$ For Sub-Saharan Africa a reasonable payment for these licenses could be in the range of $\$ 500$ million to $\$ 1$ billion per year. ${ }^{24}$ Adding a subsidy for distribution of the drugs, which would guarantee that the treatment does not cost more than 40 percent of GDP per capita in a specific country, would require additional funds. Based on prices of generic substitutes, a cocktail of three AIDS/HIV drugs may be expected to cost between $\$ 400$ and $\$ 600$ dollars per patient per year. Thus, the subsidy from the Fund would sum up to a maximum total cost of $\$ 4.7$ billion - $\$ 8.1$ billion per year for all HIV infected individuals in Sub-Saharan Africa. This funding, however,

license, with sales intended for designated recipient countries, its expanded output could provide it with a competitive advantage in non-participating countries by virtue of increasing returns to scale.

${ }^{23}$ Examples of drugs for an initial portfolio include 3TC, Zerit, Viramune, Stocrin, Combivir (AZT plus 3TC) and Crixivan.

${ }^{24}$ The lower bound of these license payments would be $\$ 442$ million per year and is based on the assumption of a portfolio with ten patents, an average R\&D cost of \$360 million per drug (Danzon, 1997), a patent length of 20 years with approval coming eight years after the patent was filed, a five percent discount rate and a 75 percent contribution to development costs from the Fund (with the remainder bbeing covered by profits from high-income markets). The upper bound would be $\$ 1.165$ billion per year and is based on the same assumptions with the discount rate changed to ten percent and the Fund's contribution to development costs raised to 100 percent. 
would not be a substitute for the $\$ 3$ billion dollars WHO and UNAIDS estimate to be needed for basic care and prevention efforts. The total cost for an international strategy is, therefore, in the range of $\$ 8.2$ to $\$ 12.1$ billion dollars annually. According to the OECD, total levels of official development assistance from bilateral donors and multilateral agencies amounted to $\$ 84.9$ billion in 1999 , two percent of which was devoted to basic health needs. ${ }^{25}$ Thus, this commitment would represent a substantial portion of the current aid funding. However, it would correspond only to $0.03-0.05$ percent of total GDP in the OECD countries in 1998. To put this in further perspective, if this amount were fully paid by the United States, the European Union, and Japan, it would come to only $\$ 13.50$ per person per year. In another view, $\$ 12.1$ billion may be compared with the anticipated loss in South African GDP of \$22 billion in the year 2010 .

\section{Concluding Remarks}

The poorest nations of the world suffer from extreme disease burdens, which go largely untreated because weak incomes and the prevailing system of intellectual property rights fail to provide sufficient incentives to develop new treatments and distribute them at low cost. Recent price reductions for HIV/AIDS drugs are encouraging but offer only a limited solution.

In this paper, we analyzed the economic tradeoffs involved in supporting drug and vaccine research through exclusive rights and distributing the fruits of that research to poor countries. Such research is expensive and would not be undertaken by private firms without some prospect for recovering expected R\&D costs. However, even if they were developed, private property rights to the distribution of these drugs, in the form of patents

\footnotetext{
${ }^{25}$ See www.oecd.org/dac/htm/dacstats.htm.
} 
and EMRs, could support inefficiently high prices and generate large deadweight welfare losses compared to the social optimum in poor countries. This system fails to account for the strong external benefits of providing additional treatments and vaccines in poor countries. These benefits accrue also to the rich countries, both for reasons of humanity and because lower economic activity in developing countries is costly in trade terms.

We offer a proposal to overcome these incentive problems. Our DEFEND ("Developing Economies' Fund for Essential New Drugs") proposal would work within the existing international legal structure but significantly would raise the returns to $R \& D$ in critical medicines and expand distribution programs. A public international organization would purchase the license rights for designated areas and distribute the drugs at low cost with a required co-payment from local governments. Furthermore, governments would restrict parallel trade to support desirable price discrimination. Costs would be funded largely by increased foreign assistance from the developed nations, but these costs would be low in relation to current aid budgets. We believe a strong program could be mounted for $\$ 8$ billion to $\$ 12$ billion per year and would be an extremely effective use of foreign aid. 


\section{REFERENCES}

Abbott, Frederick M. (2000), "The TRIPS-Legality of Measures Taken to Address Public Health Crises: Responding to USTR-State-Industry Positions that Undermine the WTO," Florida State University, manuscript.

Barton, John (2001), "Draft on Tiered Pricing for WG-4," Stanford University Law School, manuscript.

Danzon, Patricia M. (1997), Pharmaceutical Price Regulation: National Policies versus Global Interests, Washington DC: The American Enterprise Institute.

Fink, Carsten (2000), "Patent Protection, Transnational Corporations, and Market Structure: A Simulation Study of the Indian Pharmaceutical Industry," manuscript, The World Bank.

Gorlin, Jacques J. (1999), An Analysis of the Pharmaceutical-Related Provisions of the WTO TRIPS (Intellectual Property) Agreement, London: Intellectual Property Institute.

Hausman, J. and J. MacKie-Mason (1988), "Price Discrimination and Patent Policy", Rand Journal of Economics 19, 253-65

Lanjouw, Jean O. (1998), "The Introduction of Pharmaceutical Patents in India: Heartless Exploitation of the Poor and Suffering?" NBER working paper 6366.

Maskus, Keith E. (2000a), Intellectual Property Rights in the Global Economy, Washington DC: Institute for International Economics.

Maskus, Keith E. (2000b), "Parallel Imports," The World Economy: Global Trade Policy $200023,1269-1284$.

Rozek, Richard P. and Ruth Berkowitz (1998), "The Effects of Patent Protection on the Prices of Pharmaceutical Products: Is Intellectual Property Protection Raising the Drug Bill in Developing Countries?" The Journal of World Intellectual Property 1, 179-243.

Sachs, Jeffrey, Michael Kremer and Amar Hamoudi, (1999) "The Case for a Vaccine Fund," Center for International Development, Harvard University, at www.cid.harvard.edu/cidsocialpolicy/policypapers.htm.

Subramanian, Arvind (1995), "Putting Some Numbers on the TRIPS Pharmaceutical Debate," International Journal of Technology Management 10, 252-268.

Subramanian, Arvind (2001), "The AIDS Crisis, Differential Pricing of Drugs, and the TRIPS Agreement: Some Notes," International Monetary Fund, manuscript. 
Varian, Hal (1988), "Price Discrimination", in Handbook of Industrial Organization, R. Schmalensee and R. Willig (eds), North-Holland, Amsterdam, The Netherlands

Watal, Jayashree (1999), "Introducing Product Patents in the Indian Pharmaceutical Sector: Implications for Prices and Welfare," World Competition 20: 5-21.

World Health Organization, 1996, Investing in Health Research and Development: Report of the Ad Hoc Committee on Health Research Relating to Future Intervention Options. Geneva: World Health Organization. 
Table 1. Deaths and DALYs Caused by HIV/AIDS, Tuberculosis, and Malaria, 1999 (000s)

\begin{tabular}{llllllllc}
\hline Disease & World: & World: & Africa: & Africa: & Americas: & Americas: & SE Asia: & SE Asia: \\
\hline & Deaths & DALYs & Deaths & DALYs & Deaths & DALYs & Deaths & DALYs \\
HIV/AIDS & 2673 & 89819 & 2154 & 74449 & 81 & 2815 & 360 & 8866 \\
TB & 1669 & 33287 & 357 & 8721 & 59 & 1114 & 723 & 14101 \\
Malaria & 1086 & 44998 & 953 & 36838 & 2 & 76 & 69 & 3071 \\
\hline
\end{tabular}

Source: World Health Organization, World Health Report 2000 (Geneva, 2000). 
Table 2. International Price Comparison for a Selection of HIV/AIDS drugs, 2001

Panel A. Prices in the USA, Sweden and South Africa, March 2001 (in USD)

\begin{tabular}{lrrrr}
\hline Product & Sweden & USA & South Africa & South Africa \\
\hline US brand & original mnf. & original mnf. & original mnf. & generic subs. \\
\hline 3TC & 1709 & 3271 & 232 & $98-190$ \\
Zerit & 3078 & 3589 & 252 & $47-70$ \\
Viramune & 2565 & 3508 & 483 & $202-340$ \\
Stocrin & 3231 & 4730 & 500 & 1179 \\
Combivir & 4535 & 7093 & 730 & $293-635$ \\
Crixivan & 3339 & 6016 & 600 & 2300 \\
\hline
\end{tabular}

Note: Prices are for yearly treatment of a single adult patient with regular dosage.

Source: Wall Street Journal 3/7/2001; LINFO, http://www.linfo.se/fass/

Panel B. Prices as share of GDP per capita (in percent)

\begin{tabular}{lrrrr}
\hline Product & Sweden & USA & South Africa & South Africa \\
\hline US brand & original mnf. & original mnf. & original mnf. & generic subs. \\
\hline 3TC & 6.3 & 10.1 & 7.2 & $3.0-5.9$ \\
Zerit & 11.4 & 11.1 & 7.8 & $1.5-2.2$ \\
Viramune & 9.5 & 10.8 & 15.0 & $6.3-10.6$ \\
Stocrin & 11.9 & 14.6 & 15.5 & 36.6 \\
Combivir & 16.8 & 21.9 & 22.6 & $9.1-19.7$ \\
Crixivan & 12.3 & 18.6 & 18.6 & 71.4 \\
\hline
\end{tabular}

Note: GDP per capita, 1998. The exchange rates in 1998 were on average $1 \mathrm{USD}=5.54 \mathrm{ZAR}$

and $1 \mathrm{USD}=7.95 \mathrm{SEK}$ and in 2001 (until 3/25/2001) on average $1 \mathrm{USD}=7.81 \mathrm{ZAR}$ and

$1 \mathrm{USD}=9.69$ SEK .

Source: The World Bank, World Development Indicators 2000; OECD,

Main Economic Indicators may 2000 